\title{
"Don't be humble and forgiving" : Bitcoin, Paypal, xenophobia, Tolstoy and drones - and other strange times at Cayman National Bank.
}

\author{
Camille Akmut
}

November 27, 2019

\author{
Abstract \\ Partial inventory of an uncertain archive ("Sherwood").
}




\section{Bitcoin : "power to the people", or big business?}

Description - After recalling his younger, college years (COBOL, etc.), a banker draws a sociology of the various cultures surrounding cryptocurrencies, here Bitcoin (i.e. democratic visions and capitalist profit). But, "how do banks like ourselves get involved?", he asked in 2014 - is the age-old question.

RE: Conference

May 23, 2014.

E-mail from Lee Penrose ("Senior Fiduciary Executive") to Mikael More.

\section{Had they listened...}

Description - In 2009, someone "in the encryption business" contacted this bank to warn them of unencrypted e-mails being "as private as postcards".

FW: Letter from -redacted-

April 14, 2009.

E-mail from Ian Bancroft to Andrew Cubbon.

\section{Bye arithmetic}

"I paid the translator $£ 40$ personally ... I suggest ... you bill ... £100."

Bye Bye Limited

December 21, 2004.

E-mail from Eammon Harkin to Sinead Barry.

\section{A customer disappeared...}

"We are trying to contact the above lady in connection with ..."

Donna -redacted-

July 11, 2003.

E-mail from Murray Lambden to Dan Martiuk. 


\section{Paypal and Cayman Islands-style banking}

Description — not available 'yet'.

“... spoke to PayPal, unless we have a US bank a/c on US soil, we can't transfer in USD regardless of whether we have a USD bank a/c.

They are looking at giving this functionality, however it won't be this year."

PayPal

April 10, 2014.

E-mail from Alan Donnelly to Gary Kermode.

\section{Xenophobia, just another day at Cayman National}

Description - 'Harmless banter', they'll say, or they thought...

FW: The Most Pointless Family Photo of the Year! [Scanned] July 24, 2007.

Group e-mail (Lynsdey Clark et al.).

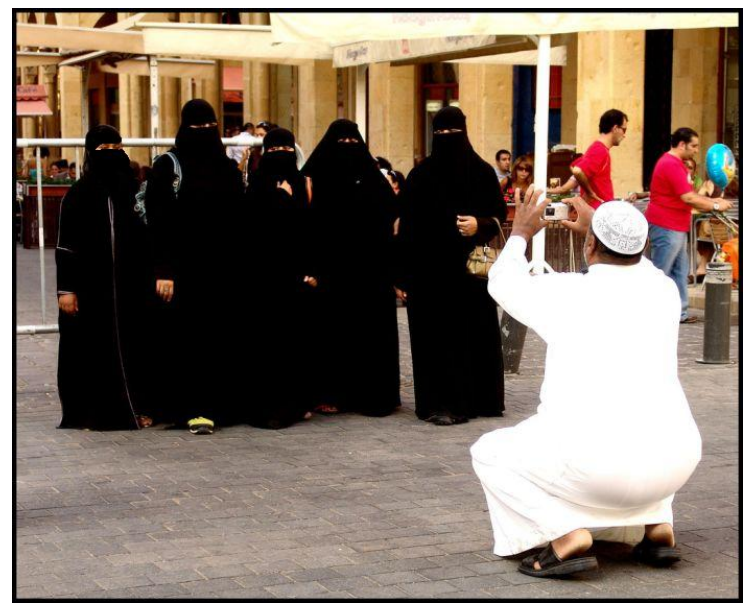

PointlessFamilyPhotooftheYear.jpg

\section{Tolstoy found in a bank's archives...}

Description - Reader of distinguished tastes Ian Bancroft sends a copy of Anna Karenina... "Every unhappy family is unhappy in its own way." 
Tolstoy could have written about this bank, their employees, and their customers, too.

Emailing Anna-Karenina-1.pdf

October 3, 2012

\section{Folly of a startup}

Description - 'Humans carried in drones' was their pitch. Endorsed by startup accelerator Techstars. As to why these former Google and IBM employees, and PhD's in aerospace engineering, would need an account on the Isle of Man, is anyone's guess. (Either they're reinventing planes, or engineering an accident...)

FW: Techstars/flugauto: opening bank account

February 5, 2018

E-mail from Barry Williams to Becky Fulton and Aaron Deehan.

\section{Anti-social behaviors}

Description — strange times indeed...

- The velvet was pure $\mathrm{s}^{* * *}$ ! It would be impossible to go any lower, Maccy D's, maybe!

- She’s trying to sell it, for $£ 90 K$ !

RE: Christmas Party

August 16, 2013 